\title{
BMJ Open MicroRNA-17 and the prognosis of human carcinomas: a systematic review and meta-analysis
}

\author{
Chengzhi Huang, ${ }^{1,2}$ Mengya Yu, ${ }^{1,3}$ Xueqing Yao ${ }^{1,2,3}$
}

To cite: Huang C, Yu M, Yao X. MicroRNA-17 and the prognosis of human carcinomas: a systematic review and meta-analysis. BMJ Open 2018;8:e018070. doi:10.1136/ bmjopen-2017-018070

- Prepublication history and additional material for this paper are available online. To view these files, please visit the journal online (http://dx.doi. org/10.1136/bmjopen-2017018070).

Received 6 June 2017 Revised 1 May 2018 Accepted 14 May 2018
Check for updates

1Department of General Surgery, Guangdong General Hospital and Guangdong Academy of Medical Sciences, Guangzhou, Guangdong, China

${ }^{2}$ Medical College, Shantou University, Shantou, Guangdong, China

${ }^{3}$ The Second School of Clinical Medicine, Southern Medical University, Guangzhou, Guangdong, China

Correspondence to Dr Xueqing Yao; yjb9211@21cn.com

\section{ABSTRACT}

Objective Although the role of microRNA-17 (miR-17) has been identified as a tumour biomarker in various studies, its prognostic value in cancers remains unclear. Therefore, we performed a systematic review and meta-analysis to analyse and summarise the relationship between the miR-17 status and clinical outcome in a variety of human cancers.

Design Systematic review and meta-analysis.

Data sources PubMed, Web of Science and Embase from the first year of records to 15 May 2017.

Outcomes The patients' survival results were pooled, and pooled HRs with $95 \%$ Cls were calculated and used for measuring the strength of association between miR17 and the prognosis of cancers, including hepatocellular carcinoma, lung cancer, osteosarcoma, glioma, T-cell lymphoblastic lymphoma and colon cancer. Heterogeneity, publication bias and subgroup analysis were also conducted.

Results A total of 1096 patients were included in this meta-analysis from 12 articles. The results indicated that the increased expression of miR-17 played an unfavourable role in overall survival in various human carcinomas with the HR of 1.342 taking into account the publication bias. In subgroup analysis, HR of ethnicity (Caucasian HR=1.48 and Asian $\mathrm{HR}=1.40$ ), disease (digestive system $\mathrm{HR}=1.36$ and blood system cancer ( $\mathrm{HR}=2.38)$, detection method (quantitative real-time $\mathrm{PCR} H R=1.40$ and in situ hybridisation, $\mathrm{HR}=2.59$ ) and detection sample (tissue $\mathrm{HR}=1.45$ and serum $\mathrm{HR}=1.32$ ) were significant with $p<0.05$. For the analysis of diseasefree survival and recurrence-free survival, the increased expression of miR-17 was associated with unfavourable prognosis $(\mathrm{HR}=1.40)$.

Conclusions miR-17 may be a useful biomarker in predicting the clinical outcome of human cancers, but due to the limitations of the current studies, further verification of the role of miR-17 in human malignancies is urgently needed.

\section{PROSPERO registration number CRD42017065749}

\section{INTRODUCTION}

Despite significant advances in clinical research over the past few decades, cancer is still a key health burden and a leading cause of death worldwide. In the year 2017, it is estimated that 1688780 patients were diagnosed with cancers with 600920 cancer deaths in

\section{Strengths and limitations of this study}

This is the first meta-analysis that summarised and reported the microRNA-17 as a novel potential cancer prognostic biomarker in the clinical field.

- We used strict, broad search strategy of the internet databases to minimise any potential publication bias.

- We conducted the subgroup analysis and found that the upregulated expression of microRNA-17 may imply poor clinical outcome in digestive system cancers.

- The major limitation of our meta-analysis is the inclusion of a limited number of studies carried out on Western populations decreasing the applicability of our results among other ethnicities. MicroRNA-17 detection is not routine clinical practice, and the prognostic value of microRNA-17 remains controversial. In the future, additional clinical trials are needed to verify the prognostic significance of microRNA-17.

the USA. ${ }^{1}$ Due to the advanced screening methods and adjuvant systemic therapies for newly diagnosed cases, the mortality rate for cancers is declining in the developed countries, ${ }^{2}$ whereas the clinical outcome of cancers in the low/middle-income countries is still poor. ${ }^{34}$

There are several independent factors for identifying and evaluating the clinical outcome of human cancers, including tumour size, histological grade, age of the patients and metastasis to lymph nodes. ${ }^{5-8}$ Tissuebased and serum-based tumour biomarkers are widely used to predict the prognosis of neoplasms. However, these techniques are far from satisfactory due to the low specificity and sensitivity. ${ }^{9-11}$ Thus, a less-invasive and more accurate biomarker would be of great value for the prognosis of human tumours.

The discovery of microRNAs (miRNAs) provided an innovative method for the prognosis of cancers by a less-invasive detection method. ${ }^{12}$ miRNAs, a class of endogenous non-coding single-stranded RNAs with the 
length of 18-25 nucleotides, act as regulators of gene expression by pairing with the complementary nucleotides in the 3'-untranslated regions (3'-UTR) of their target mRNAs. miRNAs may act as regulators of cell growth, proliferation, differentiation and apoptosis. ${ }^{13}$ Because of these fundamental activities, numerous studies have shown that miRNAs function as tumour suppressors or oncogenes. It has also been reported that some miRNAs are differentially expressed between tumour and non-tumour tissues, and the abnormal expression of tumour-associated miRNAs can be detected in patient's blood, cancerous tissue and faecal samples. ${ }^{14}{ }^{15}$ Recent studies have demonstrated that aberrantly expressed miRNAs, especially those acting as tumour suppressors or oncogenes, are related to cancer development, progression and patients' response to therapy. ${ }^{16-18}$ Therefore, miRNAs can be considered as useful prognostic biomarkers for various human cancers.

One such example is of miR-17 that is aberrantly expressed in patients with cancer. ${ }^{19-21}$ The miR-17 family, which includes six members, is one of the most extensively studied miRNA clusters. ${ }^{22}$ These miRNAs are located within an 800 base-pair region of human chromosome 13, play an essential role in the development of the heart, lung and human immune system. ${ }^{23}$ Recent studies have found that miR-17 may play a critical role in the development of human cancers. ${ }^{24}{ }^{25}$ Increased expression of miR-17 promotes the metastasis of lung and pancreatic cancers, suggesting its role as an oncogene. ${ }^{26}{ }^{27}$ However, other studies have reported that miR-17 inhibits tumour cell invasion and metastasis in breast cancer. ${ }^{28}$ In all, the role of miR-17 in cancer development and the exact mechanism are not yet clearly described. According to the miRBase (http://www.mirbase.org), miR-17 includes two members, miR-17-5p and miR-17-3p which are located in the sequence of miR-17 with a stem-loop structure. As a result, the detection of miR-17-5p, miR-17-3p has the same effect as detecting miR-17. ${ }^{29-33}$

Several published results indicate that the higher expression of the miR-17 is indicative of poor prognosis in patients with cancer. ${ }^{26} 2734-43$ However, several confounding factors, including race, detection method and tumour site, may affect the observations making the relationship between aberrant expression of miR-17 and the clinical outcome of patients with cancer inconsistent. We, therefore, conducted a meta-analysis of available studies to evaluate the clinical utility of miR-17 as a novel cancer prognostic indicator.

\section{MATERIAL AND METHODS}

\section{Data source and search strategy}

The following online electronic databases were used for the literature search: PubMed, Web of Science and Embase. The search period was up to 15 May 2017. Key search words used were: (1) prognosis OR prognostic OR survival OR outcome OR mortality; (2) cancer OR tumur OR tumour OR carcinoma OR neoplasm; (3) miR-17
OR microRNA-17 OR hsa-mir-17. Details are listed in the online supplementary table 1. Additionally, we also searched the references and relevant published articles via Google Scholar.

\section{Inclusion and exclusion criteria}

The inclusion criteria of the articles were: (1) the cancers were diagnosed by the histological examination or any other accepted standard, (2) miR-17 was studied in human cancers, (3) the expression of miR-17 and the clinical outcome of patients were included in the research and (4) reports with survival outcome and the data analysed HR with 95\% CI and HR with a p value.

The exclusion criteria were: (1) duplicate publications; (2) articles focused on other genes; (3) case reports, reviews, letters and animal trails; (4) unqualified or insufficient data; (5) HR, 95\% CI and $\mathrm{p}$ value were not provided or could not be calculated and (6) articles concentrated on the polymorphisms or methylation patterns of miRNAs.

Questions of suitability of articles to be included were examined and discussed by the authors after reviewing the abstract and full-text manuscript. The final decision was made by the academic committee.

\section{Data extraction and quality assessment}

All included studies were decided by the two investigators ( $\mathrm{CH}$ and $\mathrm{XY}$ ) independently based on titles and abstracts. Full text of the articles was required if the articles were potentially suitable for the meta-analysis. Furthermore, the literature search was performed again in the excluded articles to avoid missing any article potentially relevant for the study. The original authors of the articles were contacted if any supplementary data were needed. Any disagreement was resolved by the two authors $(\mathrm{CH}$ and $\mathrm{XY})$. The extracted details of the articles were as follows: (1) publication information: the name of the authors, publication area and publication year; (2) patient's characteristics: diseases, stage of the disease, RNA detection method, type of tissue sample and follow-up years; (3) the measurement of miR-17 measurement and its cut-off value and (4) HR of miR-17 for overall survival (OS), disease-free survival (DFS) and recurrence-free survival (RFS), as well as their 95\% CI and $\mathrm{p}$ values. The HRs and their $95 \%$ CI were extracted from the original articles or via emails from the authors. If not, we calculated HR and 95\% CI using the data of observed deaths, cancer recurrences or the original data provided by the authors. All calculations mentioned above were based on the methods provided by Parmar et al. ${ }^{44}$ The quality of the included articles was assessed based on a systematic review checklist of the Dutch Cochrane Centre proposed by Meta-analysis Of Observational Studies in Epidemiology . ${ }^{45}$

\section{Statistical analysis}

The test of heterogeneity of pooled HRs was carried out by using Cochran's $Q$ test and Higgins $I^{2}$ statistic. A p value of $<0.05$ or $\mathrm{I}^{2}>50 \%$ was considered as statistically significant. 


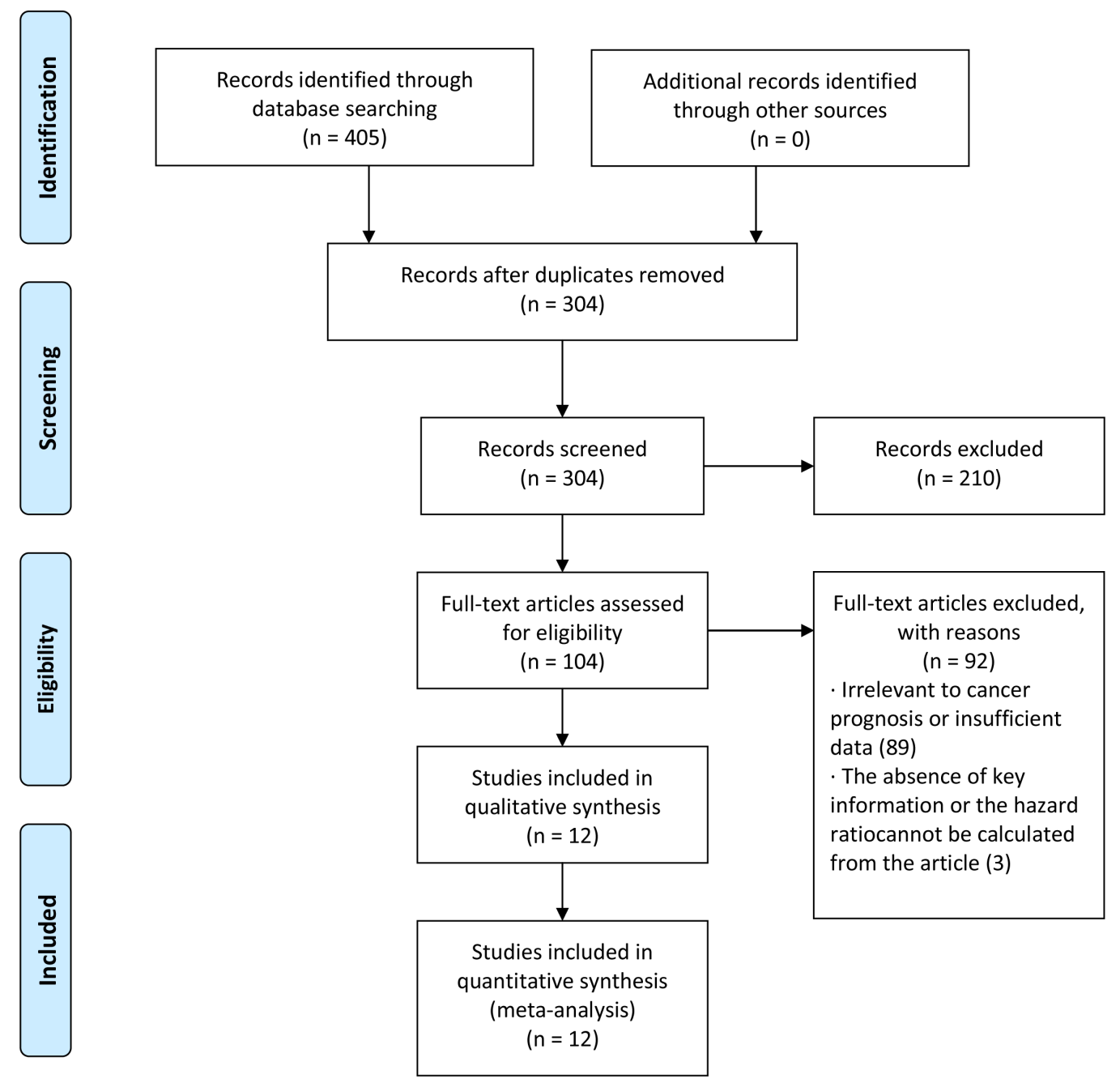

Figure 1 Flow diagram of the studies selection phase.

The $95 \% \mathrm{CI}_{\text {of }} \mathrm{I}^{2}$ was calculated by the method introduced by Hedges $e t a l .{ }^{46}$ If heterogeneity existed, the random-effects model was performed among the included studies; otherwise, the fixed-effects model was selected. $\mathrm{I}^{2}$ value ranged from $0 \%$ to $100 \%$. All $p$ values were two sided.

HR $>1$ presents of upregulated expression of miR-17 indicated poor prognosis in patients, and $\mathrm{HR}<1$ suggested a better prognosis. Publication bias was evaluated by the Begg's test and Egger's test. ${ }^{47}{ }^{48}$ If the publication bias did exist, the trim and fill method introduced by Duval and the Tweedit's was used to adjust the results. ${ }^{49}$ The STATA software V.14.0 (StataCorp) was used in all of the statistical analyses.

\section{Patients and public involvement statement}

The patients or public were not involved in the study.

\section{RESULTS}

\section{Literature selection}

We started with 405 articles associated with miR-17 and cancer prognosis was identified from online database searches. After removing the replicate records, 304 miR-17-related articles were left. The first screening based on the species, article type and language eliminated 210 citations from the analysis. Subsequently, the remaining 104 studies were carefully assessed by reviewing the abstract and full text of each article. After that, 89 articles were excluded from the study because they were unrelated to miR-17 expression levels or because of the lack of survival statistics such as HRs, $95 \%$ CI or p value. Finally, 15 studies, which investigated the potential relationship between miR-17 expression and prognosis of human cancers, remained for further detailed screening and data extraction. Three of the studies that explained the relationship between miR-17 expression and the clinical outcome of cancer had to be removed because the authors did not provide the exact HR value, or the value cannot be calculated from the data. Thus, 12 articles (12 studies) ${ }^{262734-43}$ were included in this meta-analysis (figure 1).

\section{Characteristics of selected studies}

All 12 studies included in the meta-analysis were retrospective studies published between 2010 and $2016 .{ }^{262734-43}$ Patient's OS was reported in all 12 studies, and 3 studies also examined the DFS or RFS. The type of the cancers 
Table 1 A summary table of the meta-analysis

\begin{tabular}{|c|c|c|c|c|c|c|c|c|c|c|c|}
\hline Study & Year & Country & Diseases & Case no & Stage & Sample & Assay & $\begin{array}{l}\text { Cut-off } \\
\text { value }\end{array}$ & HR & $\begin{array}{l}\text { Follow- } \\
\text { up } \\
\text { (months) }\end{array}$ & $\begin{array}{l}\text { Type of } \\
\text { miR-17 } \\
\text { detection }\end{array}$ \\
\hline Chen et $\left.\mathrm{al}\right|^{37}$ & 2012 & China & $\mathrm{HCC}$ & 120 & I-IV & Tissue & qRT-PCR & Median & $\mathrm{RR}$ & 46 & $\operatorname{miR}-17-5 p$ \\
\hline Qun et $a l^{27}$ & 2013 & China & Lung cancer & 221 & I-IV & Tissue & qRT-PCR & Median & Given & 50 & miR-17 \\
\hline Li et $a l^{41}$ & 2014 & China & Osteosarcoma & 117 & I-III & Tissue & qRT-PCR & Median & Given & 44 & miR-17 \\
\hline Lu et $a l^{35}$ & 2012 & China & Glioma & 108 & I-IV & Tissue & qRT-PCR & Mean & $\mathrm{RR}$ & 60 & miR-17 \\
\hline Yu et al ${ }^{40}$ & 2012 & China & Colon cancer & 48 & I-IV & Tissue & qRT-PCR & Median & Given & $5-66$ & miR-17 \\
\hline Manuel et $a l^{39}$ & 2011 & Spain & $\begin{array}{l}\text { Gastrointestinal } \\
\text { cancer }\end{array}$ & 38 & I-IV & Tissue & qRT-PCR & Mean & Given & 38 & miR-17 \\
\hline Jun et $a l^{26}$ & 2010 & Japan & $\begin{array}{l}\text { Pancreatic } \\
\text { cancer }\end{array}$ & 80 & I-IV & Tissue & qRT-PCR & Median & Given & 60 & $m i R-17-5 p$ \\
\hline Wang et $a l^{43}$ & 2011 & China & Gastric cancer & 65 & I-IV & Serum & qRT-PCR & Median & Given & 36 & $\operatorname{miR}-17-5 p$ \\
\hline Zheng et $a /^{34}$ & 2013 & China & $\mathrm{HCC}$ & 96 & I-IV & Serum & qRT-PCR & Median & Given & $N G$ & miR-17-5p \\
\hline
\end{tabular}

HCC, hepatocellular carcinoma; ISH, in situ hybridisation; miR-17, microRNA-17; NG, not given; OS, overall survival; qRT-PCR, quantitative real-time PCR; RR, risk ratio.

included gastrointestinal cancers (colorectal cancer, gastric cancer), lung cancer, pancreatic cancer, hepatocellular cancer, osteosarcoma, glioma, T-cell lymphoblastic lymphoma and oesophageal squamous cell carcinoma. A total of 1096 patients with various types of cancers were from People's Republic of China, Japan, Spain and Brazil. Quantitative real-time PCR (qRT-PCR) was used to assess the expression of miR-17 in 12 studies, and 1 study used the in situ hybridisation (ISH). All studies used tissue and serum samples as the source of the miR-17. The majority (10 of 12) of the HRs reported in the present analysis were included in the multivariate analysis. The remaining two HRs could be estimated by Kaplan-Meier analysis and relative risk values. Most of the studies have the follow-up research for at least 38 months. The clinical characteristics of the studies included in this article are summarised in table 1.

\section{Association between miR-17 and OS}

Due to low heterogeneity, fixed-effects model was used to calculate and analyse the pooled HR value. High expression level of miR-17 was associated with the poor OS in patients with diverse cancers. The statistical power of $\mathrm{Q}$ test is low when there are limited studies included in the meta-analysis. We, therefore, conducted random-effect analysis on the OS (HR 1.45, 95\% CI 1.29 to $1.63, \mathrm{p}<0.001$ ), which was not significantly different compared with the analysis of fixed-effect model. Details of the meta-analysis are systematically summarised in the figure 2.
To demonstrate the predictive role of miR-17, subgroups analysis was conducted based on patients' ethnicity, cancer type, methods identifying miRNAs and type of tissue samples. Clinical association between miR-17 and OS was found in the Asian and Caucasian patients (figure 3A). The association was also significant in other subgroups, including digestive system cancers and blood cancers (figure 3B), qRT-PCR detection method (figure 3C), and tissue and serum samples (figure 3D). miR-17 includes two members, miR-17-5p and miR-17-3p which are located in the sequence of miR-17 with a stem-loop structure. Therefore, analysis of miR-17-5p or miR-17-3p afforded the same effect (or result) as miR-17. To clarify the heterogeneity, we conducted a subgroup analysis concerning the detection method of miR-17 and found that the clinical value was also significant in miR-17 group and miR-17-5p group. There was no significant difference between the two groups (figure 3E), implying that same effect existed when detecting miR-17 and miR-17-5p. Details of the subgroup analysis are listed in the table 2.

\section{Correlation between miR-17 and DFS and RFS}

A total of three studies ${ }^{37} 38$ were included in the analysis of DFS and RFS. The analyses revealed a predictive role of increased expression of miR-17 for the prognosis of patients with cancer (pooled HR 1.40, 95\% CI 1.23 to $1.60, \mathrm{p}<0.001)$ as determined by the fixed-effect model $\left(\mathrm{I}^{2}=15.8 \%, \mathrm{p}=0.305\right)$ (figure 4$)$. 


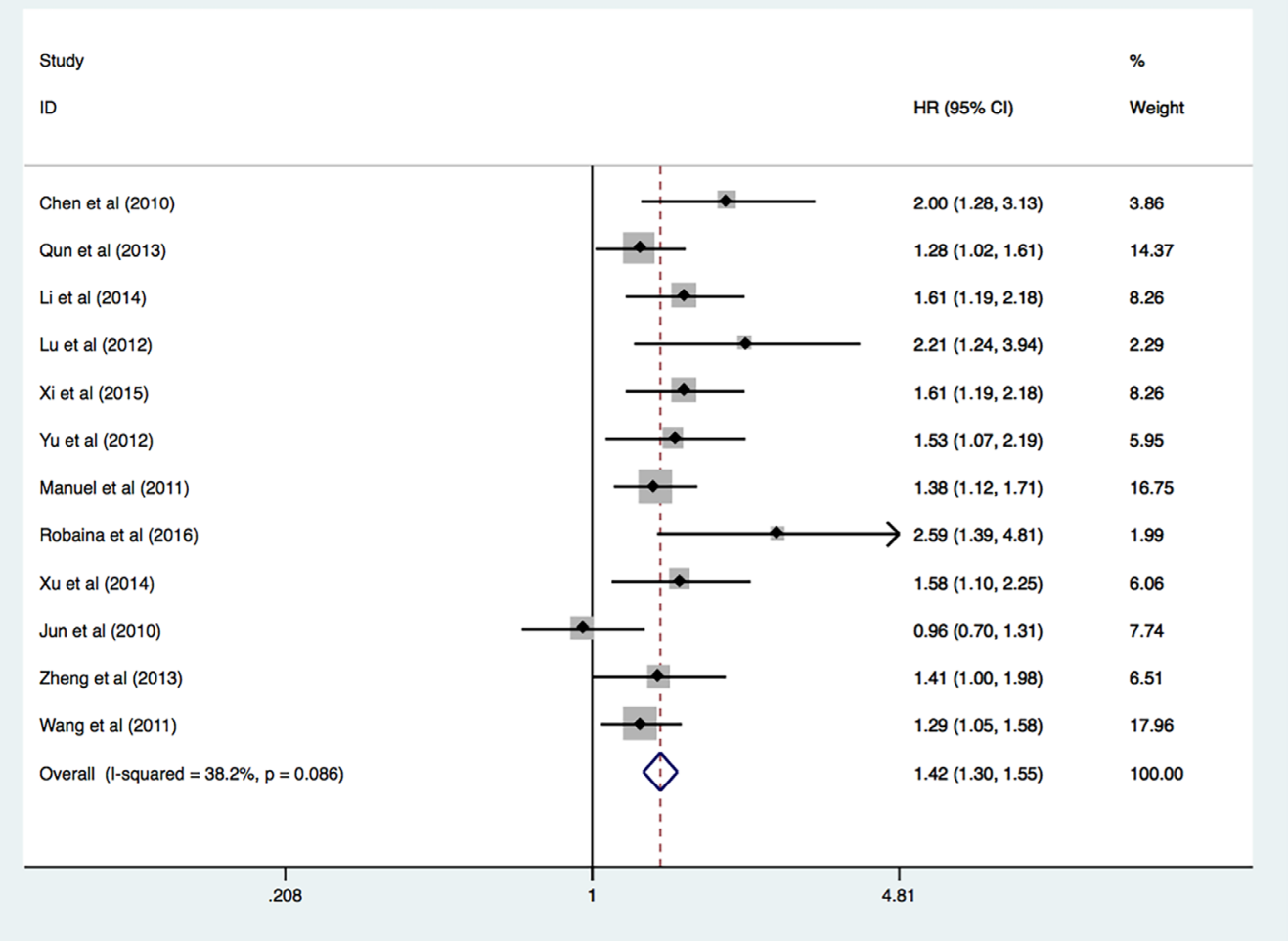

Figure 2 Forest plot of meta-analysis of overall survival in association with miR-17 expression.

\section{Publication bias}

We used Begg's funnel plot and Egger's test to assess the possible publication bias of the included studies. ${ }^{47} 48 \mathrm{In}$ the analysis of relationship between miR-17 and the OS, the p values of Egger's test and Begg's test were 0.014 and 0.011 , respectively. The funnel plot and Egger's plot are displayed in figure 5A,B. Both Begg's test and Egger's test implied a publication bias, thus, the trim and fill method was performed to make pooled HR more reliable. ${ }^{49}$ The altered HR was $1.34,95 \%$ CI 1.24 to $1.46, \mathrm{p}<0.001$, which was not significantly different from the pooled HR (online supplementary figure 1).

\section{DISCUSSION}

Previous studies have shown that miRNAs have a distinct expression profile in cancerous tissues which can be detected by qRT-PCR in frozen, formalin-fixed and paraffin-embedded tissues and in serum samples. Recently, miRNAs, serving as tumour suppressors or oncogenes, have been shown to play important roles in the evolution and progression of cancers. miRNAs are involved in a variety of crucial cellular pathways such as angiogenesis, innate and adaptive immune responses, cellular proliferation, invasion and metastasis. ${ }^{12}{ }^{16}$ Several studies have reported the potential use of miRNAs as tumour biomarkers for detecting tumour occurrence, development and prognosis. Unfortunately, effective diagnosis techniques and prognosis indicators of cancer have not been found. Developing a novel less-invasive detection method with higher accuracy for cancer prognosis is of great significance in evaluating cancer progression as well as monitoring patients' therapeutic response.

Over the last couple of decades, numerous studies have uncovered the involvement of miRNAs in the pathogenesis of cancer. Since miRNAs can be obtained non-invasively from the serum, urine and faecal samples, their utility as diagnostic and prognostic biomarkers in cancer and other diseases has been extensively explored. It has been reported that miRNA could be detected with higher accuracy than traditional cancer biomarkers in predicting the clinical outcome of the human colon cancers. ${ }^{50}$ However, adequate evidence is still lacking for the utility of miRNAs as cancer biomarkers in clinical practice.

miR-17, a widely studied miRNA, is aberrantly expressed in different kinds of cancers, such as glioma, ${ }^{35}$ oesophageal and oral squamous cell carcinomas, ${ }^{36} 51$ pancreatic cancer, ${ }^{26}$ gastrointestinal cancers, ${ }^{39}$ osteosarcoma ${ }^{52}$ and Burkitt lymphoma, ${ }^{38}$ and is significantly related to the clinical outcome of cancers. Our meta-analysis indicated that the elevated miR-17 expression is significantly associated with poor $\mathrm{OS}(\mathrm{HR}=1.42)$ in patients with various types of carcinomas. The analysis using the Cochran's $Q$ test and Higgins $\mathrm{I}^{2}$ test implied low heterogeneity. As limited number of studies were included in the meta-analysis, the $\mathrm{Q}$ test had inadequate statistical power. We, therefore, applied the fixed-effects model to calculate and analyse the pooled HR value. We also conducted random-effect analysis on the OS, which was not significantly different when compared with analysis of fixed-effect model (figure 2). In the subgroup analysis, we found that the 


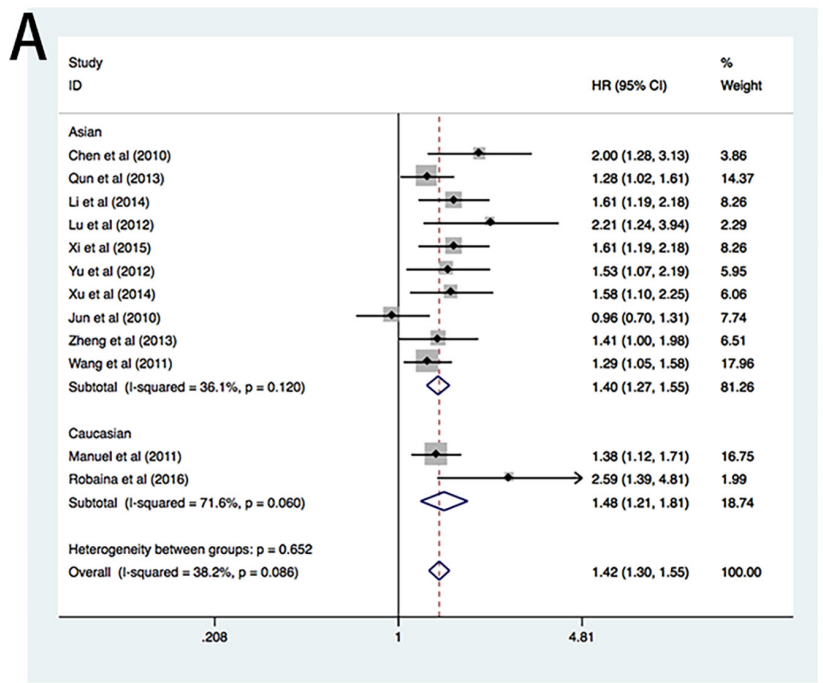

B
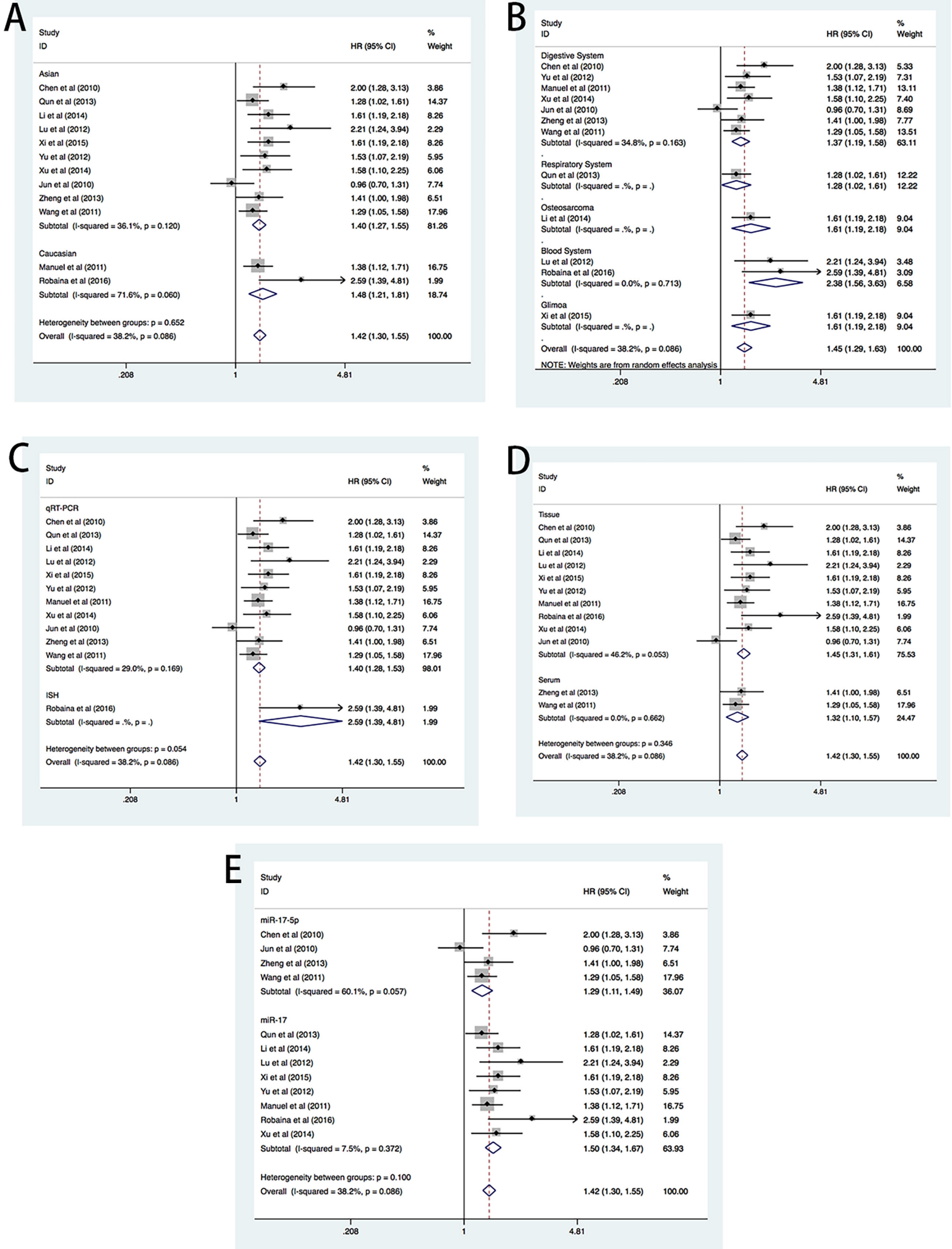

Figure 3 Forest plots of subgroup meta-analysis of OS in association with miR-17 expression. (A) Forest plots of the merged analyses of OS in different ethnic groups. Squares and lines correspond to the study-specific HRs and $95 \%$ Cls, respectively. The area of the squares represents the weight, and the diamonds represent the summary of HRs and $95 \%$ Cls. (B) Forest plots of the merged analyses of OS in different diseases groups. (C) Forest plots of the merged analyses of OS in different RNA detection methods groups. (D) Forest plots of the merged analyses of OS in different sample groups. (E) Forest plots of the merged analyses of OS in the detection method of miR-17. ISH, in situ hybridisation; miR-17, microRNA-17; OS, overall survival; qRT-PCR, quantitative real-time PCR. 
Table 2 Subgroup analysis

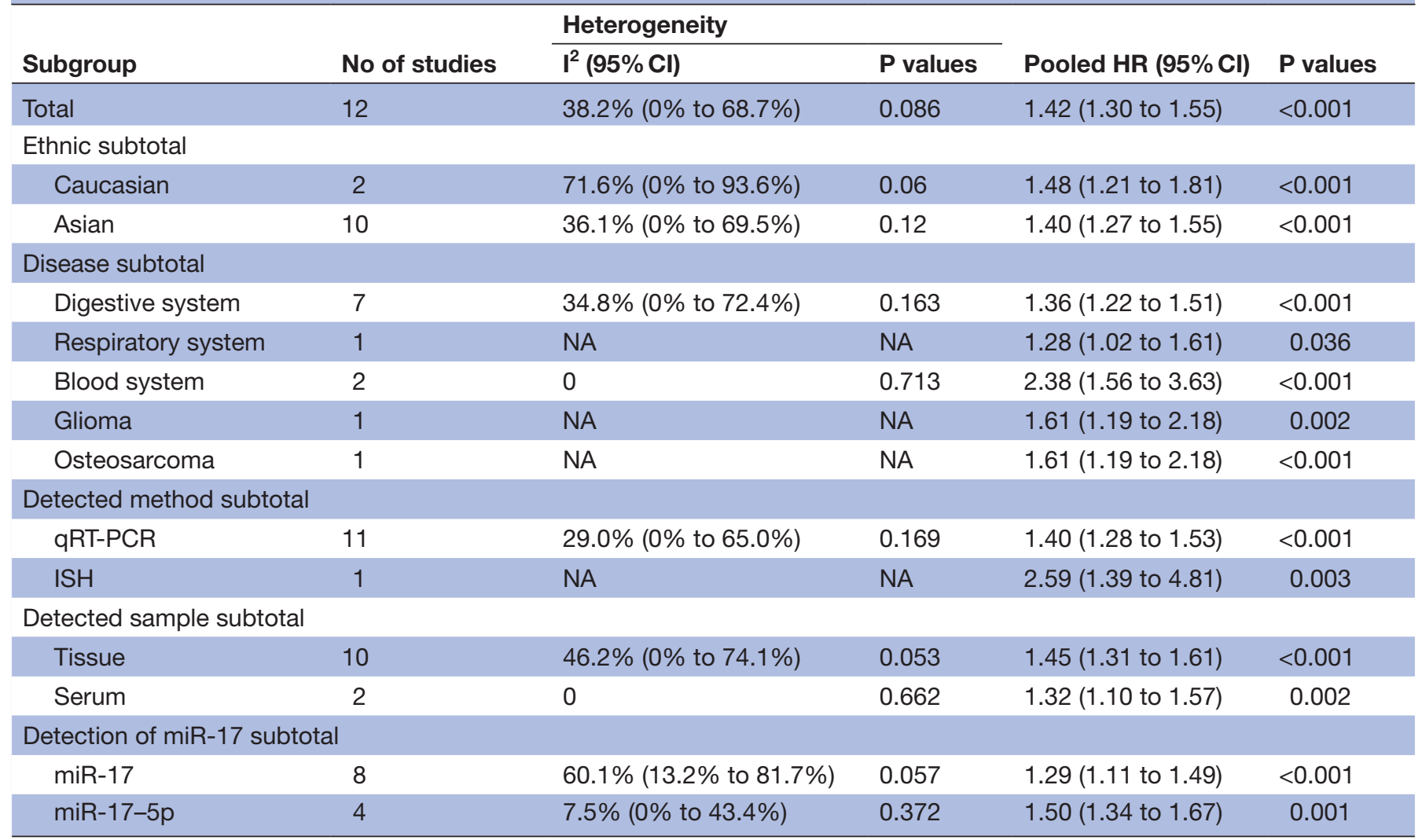

ISH, in situ hybridisation; miR-17, microRNA-17; miR-17-5p, microRNA-17-5p; NA, not available; qRT-PCR, quantitative real-time PCR.

potential heterogeneity may have originated from the Caucasian group in the study conducted by Robaina et $a l .{ }^{38}$ Unlike the commonly used RT-PCR, ISH technique was used to detect miR-17. Other factors contributing to the heterogeneity may include the limited number of patients $(n=41)$ recruited in the study. However, both studies from Spain and Brazil recruited population of Caucasians decreasing the heterogeneity.

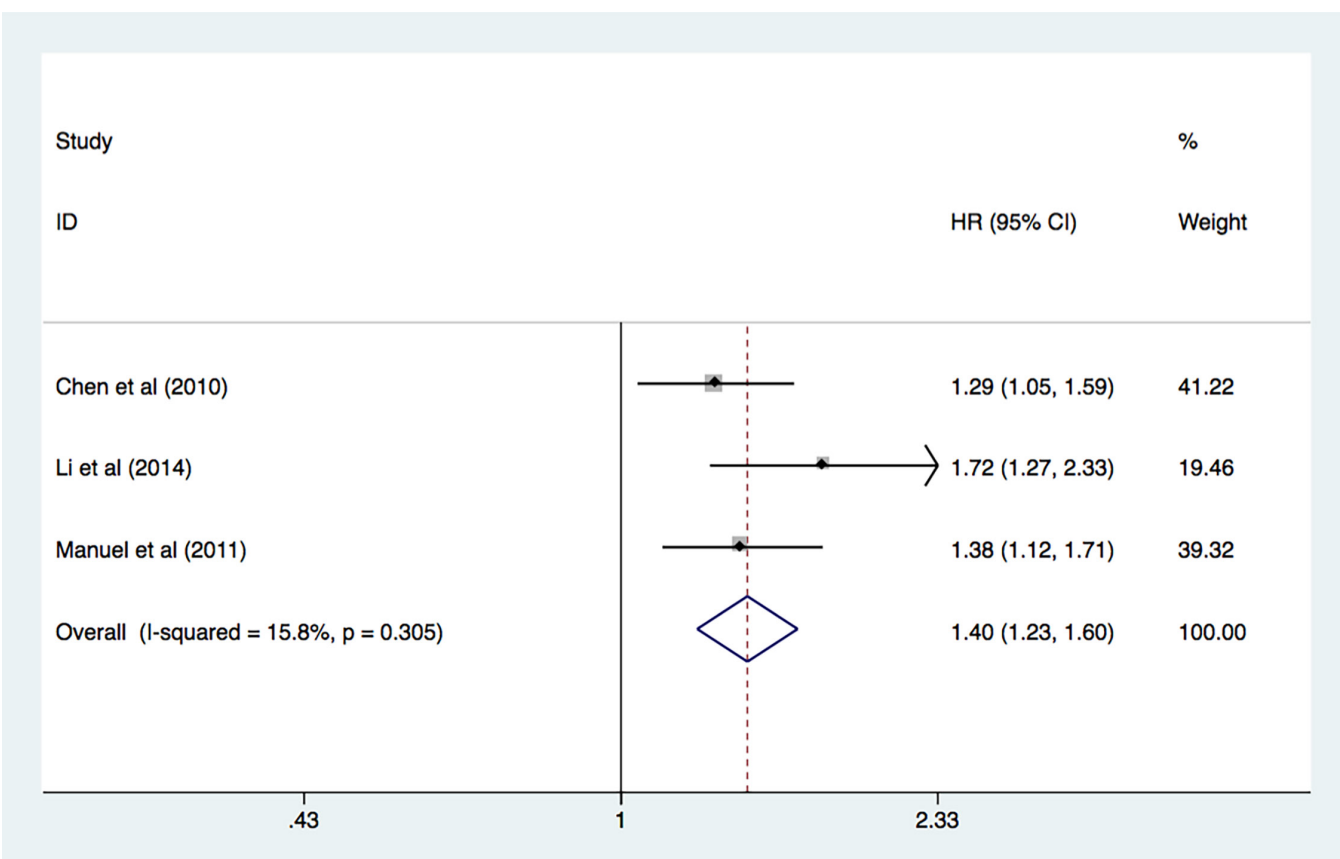

Figure 4 Forest plot of disease-free survival and recurrence-free survival in association with miR-17 expression. miR-17, microRNA-17. 

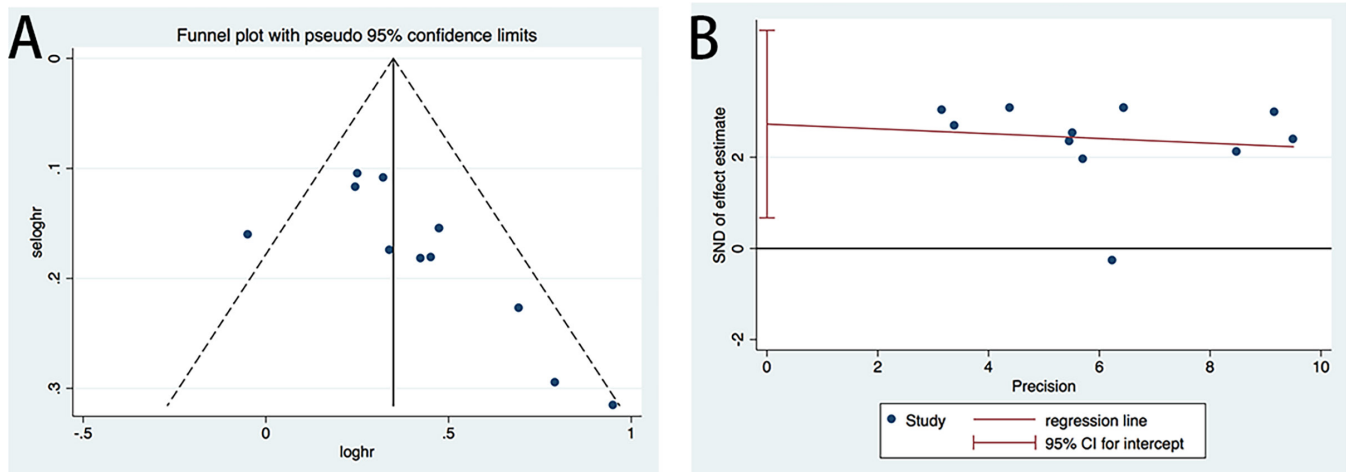

Figure 5 (A) Funnel plot of merged analysis of OS comparing high or low expression of miR-17. (B) Egger's test plot of merged analysis of OS comparing high or low expression of miR-17. miR-17, microRNA-17; OS, overall survival; SND, standard normal deviate.

As the Begg's test and the Egger's test implied publication bias, we used the trim and fill method to obtain a more reliable pooled HR. We found that the adjusted HR was not significantly different from the pooled HR. In subgroup analysis, based on the characteristics of the individual studies, significant HR was found in the Caucasian and Asian groups, the qRT-PCR group and the tissue and serum sample groups. Furthermore, the increased expression of miR-17 indicated poor DFS and RFS in hepatocellular carcinoma (HCC) and gastrointestinal cancers. Several investigators have explored the functional roles of miR-17 and its involvement in human cancers. Yang et al found that the miRNA-17 was overexpressed in the HCC tissue, and promoted the phosphorylation of heat shock protein 27 (HSP27). The phosphorylated HSP27 then enhanced the migration of the HCC cells implying a significant role of miRNA-17 in the progression of HCC. ${ }^{53}$ Wang et al reported that the upregulated expression of miRNA-17-5p promoted cancer cells proliferation and inhibited apoptosis by post-transcriptional modulation of mRNA-p21 and tumour protein p53-induced nuclear protein $1 .{ }^{54}$ In the study by Ma $e t a l$, overexpression of miRNA-17 promoted cancer cells progression by targeting $\mathrm{P} 130 .^{55}$ Yan et al found overexpression of the miR-17-5p in pancreatic cancer. The miR-17-5p inhibitor promoted the expression of Bim protein by targeting the 3'-UTR of its mRNA and negatively regulating at the post-transcriptional level. Therefore, the authors suggested that the miR-17-5p inhibitor may be a novel therapeutic approach for pancreatic cancer. ${ }^{56}$ Together with our meta-analysis, these findings suggest that the detection of tissue or serum miR-17 expression may be a useful prognostic biomarker in patients with HCC, pancreatic cancer and gastrointestinal cancers.

There are potential limitations of this study. The literature searches using authentic and widely used data bases found studies performed predominantly on Asian populations not encompassing sufficient numbers of other populations such as Caucasians. Our results of miR-17 as a potential biomarker may, therefore, not be applicable to other populations. The pooled HR values were also not sufficiently strong. Furthermore, the relatively limited sample size of 1031 patients weakened the statistical significance of the prognostic potential of miR-17 expression levels.

\section{CONCLUSIONS}

In summary, our meta-analysis suggested that miR-17 is a potential biomarker in various types of cancers. However, further multicentre clinical trials with larger sample size and prospective studies including Caucasians and patients representing other ethnicities are needed to confirm the prognostic value of miR-17 and its subsequent application as a prognostic biomarker in the routine clinical guidance of cancers.

Acknowledgements The authors thank the grants from Guangdong Science and Technology Department, China.

Contributors $\mathrm{CH}$ and $\mathrm{MY}$ conceived the study. $\mathrm{CH}$ and $\mathrm{XY}$ performed the data extraction and analysed the data. $\mathrm{CH}$ and MY wrote the paper. All authors had full access to all of the data and approved the final version of the manuscript.

Funding The article is funded by Guangdong Science and Technology Department, China. (No.2014A020212636).

Competing interests None declared.

Patient consent Not required.

Ethics approval The study does not include human participants or animals.

Provenance and peer review Not commissioned; externally peer reviewed.

Data sharing statement No additional data are available.

Open Access This is an Open Access article distributed in accordance with the Creative Commons Attribution Non Commercial (CC BY-NC 4.0) license, which permits others to distribute, remix, adapt, build upon this work non-commercially, and license their derivative works on different terms, provided the original work is properly cited and the use is non-commercial. See: http://creativecommons.org/ licenses/by-nc/4.0/

(C) Article author(s) (or their employer(s) unless otherwise stated in the text of the article) 2018. All rights reserved. No commercial use is permitted unless otherwise expressly granted.

\section{REFERENCES}

1. Siegel RL, Miller KD, Jemal A, et al. Cancer statistics, 2017. CA: A Cancer Journal for Clinicians 2017;67:7-30.

2. Torre LA, Bray F, Siegel RL, et al. Global cancer statistics, 2012. CA Cancer J Clin 2015;65:87-108. 
3. Chen W, Zheng R, Baade PD, et al. Cancer statistics in China, 2015. CA Cancer J Clin 2016;66:115-32.

4. Siegel R, DeSantis C, Virgo K, et al. Cancer treatment and survivorship statistics, 2012. CA Cancer J Clin 2012;62:220-41.

5. Fisher B, Slack NH, Bross ID. Cancer of the breast: size of neoplasm and prognosis. Cancer 1969;24:1071-80.

6. Bloom HJ, Richardson WW. Histological grading and prognosis in breast cancer; a study of 1409 cases of which 359 have been followed for 15 years. Br J Cancer 1957;11:359-77.

7. Kroman N, Jensen MB, Wohlfahrt J, et al. Factors influencing the effect of age on prognosis in breast cancer: population based study. BMJ 2000;320:474-8.

8. Fisher B, Bauer M, Wickerham DL, et al. Relation of number of positive axillary nodes to the prognosis of patients with primary breast cancer. An NSABP update. Cancer 1983;52:1551-7.

9. Schreuders EH, Ruco A, Rabeneck L, et al. Colorectal cancer screening: a global overview of existing programmes. Gut 2015;64:1637-49.

10. Nicholson BD, Shinkins B, Pathiraja I, et al. Blood CEA levels for detecting recurrent colorectal cancer. Cochrane Database Syst Rev 2015;12:CD011134

11. Sun W, Liu Y, Shou D, et al. AFP (alpha fetoprotein): who are you in gastrology? Cancer Lett 2015;357:43-6.

12. Tricoli JV, Jacobson JW. MicroRNA: Potential for Cancer Detection, Diagnosis, and Prognosis. Cancer Res 2007;67:4553-5.

13. Valencia-Sanchez MA, Liu J, Hannon GJ, et al. Control of translation and mRNA degradation by miRNAs and siRNAs. Genes Dev 2006;20:515-24.

14. Rokkas T, Kothonas F, Rokka A, et al. The role of circulating microRNAs as novel biomarkers in diagnosing colorectal cancer: a meta-analysis. Eur J Gastroenterol Hepatol 2015;27:819-25.

15. Yang X, Zhong J, Ji Y, et al. The expression and clinical significance of microRNAs in colorectal cancer detecting. Tumour Biol 2015;36:2675-84.

16. Romero-Cordoba SL, Salido-Guadarrama I, Rodriguez-Dorantes M, et al. miRNA biogenesis: biological impact in the development of cancer. Cancer Biol Ther 2014:15:1444-55.

17. Cho WC. Circulating MicroRNAs as Minimally Invasive Biomarkers for Cancer Theragnosis and Prognosis. Front Genet 2011;2:7.

18. Avery-Kiejda KA, Braye SG, Mathe A, et al. Decreased expression of key tumour suppressor microRNAs is associated with lymph node metastases in triple negative breast cancer. BMC Cancer 2014;14:51.

19. Liang Y, Yang W, Zhu Y, et al. Prognostic role of microRNA-203 in various carcinomas: evidence from a meta-analysis involving 13 studies. Springerplus 2016:5:1538.

20. Wang Z, Cai Q, Jiang Z, et al. Prognostic role of microRNA-21 in gastric cancer: a meta-analysis. Med Sci Monit 2014;20:1668-74

21. Li Y, Hong F, Yu Z. Decreased expression of microRNA-206 in breast cancer and its association with disease characteristics and patient survival. J Int Med Res 2013;41:596-602.

22. Mogilyansky E, Rigoutsos I. The miR-17/92 cluster: a comprehensive update on its genomics, genetics, functions and increasingly important and numerous roles in health and disease. Cell Death Differ 2013;20:1603-14

23. Mendell JT. miRiad roles for the miR-17-92 cluster in development and disease. Cell 2008;133:217-22.

24. Wang Q, Li YC, Wang J, et al. miR-17-92 cluster accelerates adipocyte differentiation by negatively regulating tumor-suppressor Rb2/p130. Proc Natl Acad Sci U S A 2008;105:2889-94.

25. Ottman R, Levy J, Grizzle WE, et al. The other face of miR-17-92a cluster, exhibiting tumor suppressor effects in prostate cancer. Oncotarget 2016;7:73739.

26. Yu J, Ohuchida K, Mizumoto K, et al. MicroRNA miR-17-5p is overexpressed in pancreatic cancer, associated with a poor prognosis, and involved in cancer cell proliferation and invasion. Cancer Biol Ther 2010;10:748-57.

27. Chen Q, Si Q, Xiao S, et al. Prognostic significance of serum miR-17$5 p$ in lung cancer. Med Oncol 2013;30.

28. Yu Z, Willmarth NE, Zhou J, et al. microRNA 17/20 inhibits cellular invasion and tumor metastasis in breast cancer by heterotypic signaling. Proc Natl Acad Sci U S A 2010;107:8231-6.

29. Griffiths-Jones S. The microRNA Registry, 2004

30. Kozomara A, Griffiths-Jones S. miRBase: annotating high confidence microRNAs using deep sequencing data. Nucleic Acids Res 2014:42:D68-D73.
31. Kozomara A, Griffiths-Jones S. miRBase: integrating microRNA annotation and deep-sequencing data. Nucleic Acids Res 2011;39:D152-D157.

32. Griffiths-Jones S, Grocock RJ, van Dongen S, et al. miRBase: microRNA sequences, targets and gene nomenclature. Nucleic Acids Res 2006;34:D140-D144.

33. Griffiths-Jones S, Saini HK, van Dongen S, et al. miRBase: tools for microRNA genomics. Nucleic Acids Res 2008;36.

34. Zheng J, Dong P, Gao S, et al. High expression of serum miR-17$5 p$ associated with poor prognosis in patients with hepatocellular carcinoma. Hepatogastroenterology 2013;60:549-52.

35. Lu S, Wang S, Geng S, et al. Increased expression of microRNA-17 predicts poor prognosis in human glioma. $J$ Biomed Biotechnol 2012;2012:1-6.

36. $\mathrm{Xu} X \mathrm{X}$, Jiang $\mathrm{YH}$, Feng JG, et al. MicroRNA-17, microRNA-18a, and microRNA-19a are prognostic indicators in esophageal squamous cell carcinoma. Ann Thorac Surg 2014;97:1037-45.

37. Chen L, Jiang $M$, Yuan $W$, et al. miR-17-5p as a novel prognostic marker for hepatocellular carcinoma. J Invest Surg 2012;25:156-61.

38. Robaina MC, Faccion RS, Mazzoccoli L, et al. miR-17-92 cluster components analysis in Burkitt lymphoma: overexpression of miR-17 is associated with poor prognosis. Ann Hematol 2016;95:881-91.

39. Valladares-Ayerbes M, Blanco M, Haz M, et al. Prognostic impact of disseminated tumor cells and microRNA-17-92 cluster deregulation in gastrointestinal cancer. Int J Oncol 2011;39:1253.

40. Yu G, Tang JQ, Tian ML, et al. Prognostic values of the miR17-92 cluster and its paralogs in colon cancer. J Surg Oncol 2012;106:232-7.

41. Li X, Yang H, Tian Q, et al. Upregulation of microRNA-17-92 cluster associates with tumor progression and prognosis in osteosarcoma. Neoplasma 2014;61:453-60.

42. $\mathrm{Xi}$ Y, Li J, Zhang P, et al. Upregulation of miRNA-17 and miRNA-19 is associated with unfavorable prognosis in patients with T-cell lymphoblastic lymphoma. Exp Mol Pathol 2015;99:297-302.

43. Wang M, Gu H, Wang S, et al. Circulating miR-17-5p and miR-20a: molecular markers for gastric cancer. Mol Med Rep 2012;5:1514-20.

44. Parmar MK, Torri V, Stewart L. Extracting summary statistics to perform meta-analyses of the published literature for survival endpoints. Stat Med 1998:17:2815-34.

45. Stroup DF, Berlin JA, Morton SC, et al. Meta-analysis of observational studies in epidemiology: a proposal for reporting. Meta-analysis Of Observational Studies in Epidemiology (MOOSE) group. JAMA 2000;283:2008-12.

46. Hedges LV, Pigott TD. The power of statistical tests in meta-analysis. Psychol Methods 2001;6:203-17.

47. Egger M, Davey Smith G, Schneider M, et al. Bias in meta-analysis detected by a simple, graphical test. BMJ 1997;315:629-34.

48. Begg CB, Mazumdar M. Operating characteristics of a rank correlation test for publication bias. Biometrics 1994:50:1088-101.

49. Duval S, Tweedie R. Trim and fill: A simple funnel-plot-based method of testing and adjusting for publication bias in meta-analysis. Biometrics 2000:56:455-63.

50. Schetter AJ, Leung SY, Sohn JJ, et al. MicroRNA expression profiles associated with prognosis and therapeutic outcome in colon adenocarcinoma. JAMA 2008;299:425-36.

51. Chang CC, Yang YJ, Li YJ, et al. MicroRNA-17/20a functions to inhibit cell migration and can be used a prognostic marker in oral squamous cell carcinoma. Oral Oncol 2013;49:923-31.

52. Li S, Gao Y, Wang Y, et al. Serum microRNA-17 functions as a prognostic biomarker in osteosarcoma. Oncol Lett 2016;12:4905-10.

53. Yang F, Yin $Y$, Wang F, et al. miR-17-5p Promotes migration of human hepatocellular carcinoma cells through the p38 mitogenactivated protein kinase-heat shock protein 27 pathway. Hepatology 2010;51:1614-23.

54. Wang $\mathrm{M}, \mathrm{Gu} \mathrm{H}$, Qian $\mathrm{H}$, et al. miR-17-5p/20a are important markers for gastric cancer and murine double minute 2 participates in their functional regulation. Eur J Cancer 2013;49.

55. Ma Y, Zhang P, Wang F, et al. Elevated oncofoetal miR-17-5p expression regulates colorectal cancer progression by repressing its target gene P130. Nat Commun 2012:3:1291.

56. Yan HJ, Liu WS, Sun WH, et al. miR-17-5p inhibitor enhances chemosensitivity to gemcitabine via upregulating Bim expression in pancreatic cancer cells. Dig Dis Sci 2012;57:3160-7. 


\section{Correction: MicroRNA-17 and the prognosis of human} carcinomas: a systematic review and meta-analysis

Huang $\mathrm{C}, \mathrm{Yu} \mathrm{M}$, Yao X. MicroRNA-17 and the prognosis of human carcinomas: a systematic review and meta-analysis. BMJ Open 2018;8:e018070. doi:10.1136/ bmjopen-2017-018070.

This article was previously published with some errors.

In the table 1 , table 2 and figure 1 , Robaina et al. conducted the study of miR-17 by the method of qRT-PCR instead of ISH as we described in the paper (citation number 38). Secondly, the term Caucasian is not applied in Brazilian for ethnicity classification. The authors would therefore like to use the term non-Asian for describing the studies conducted in the Spain and Brazil. The issue did not affect the main result and the conclusion of the study. Below is the updated table 2 and figure 1.

Table 1 A summary table of the meta-analysis

\begin{tabular}{|c|c|c|c|c|c|c|c|c|c|c|c|}
\hline Study & Year & Country & Diseases & $\begin{array}{l}\text { Case } \\
\text { Number }\end{array}$ & Stage & Sample & Assay & $\begin{array}{l}\text { Cut-off } \\
\text { value }\end{array}$ & HR & $\begin{array}{l}\text { Follow-up } \\
\text { (months) }\end{array}$ & $\begin{array}{l}\text { Type of miR- } \\
17 \text { detection }\end{array}$ \\
\hline Chen et al & 2012 & China & $\mathrm{HCC}$ & 120 & I-IV & Tissue & qRT-PCR & Median & $\mathrm{RR}$ & 46 & $m i R-17-5 p$ \\
\hline Qun et al & 2013 & China & Lung Cancer & 221 & I-IV & Tissue & qRT-PCR & Median & Given & 50 & miR-17 \\
\hline Li et al & 2014 & China & Osteosarcoma & 117 & I-III & Tissue & qRT-PCR & Median & Given & 44 & miR-17 \\
\hline Lu et al & 2012 & China & Glioma & 108 & I-IV & Tissue & qRT-PCR & Mean & $\mathrm{RR}$ & 60 & miR-17 \\
\hline Xi et al & 2015 & China & $\begin{array}{l}\text { T-cell lymphoblastic } \\
\text { lymphoma }\end{array}$ & 57 & III, IV & Tissue & qRT-PCR & Median & Given & $\begin{array}{l}\text { Up to } 13 \\
\text { years }\end{array}$ & miR-17 \\
\hline Manuel et al & 2011 & Spain & $\begin{array}{l}\text { Gastrointestinal } \\
\text { Cancer }\end{array}$ & 38 & I-IV & Tissue & qRT-PCR & Mean & Given & 38 & miR-17 \\
\hline Robaina et al & 2016 & Brazil & Burkitt lymphoma & 41 & I-IV & Tissue & qRT-PCR & Median & Given & 69 & miR-17 \\
\hline Xu et al & 2014 & China & $\begin{array}{l}\text { Esophageal Squamous } \\
\text { Cell Carcinoma }\end{array}$ & 105 & I-IV & Tissue & qRT-PCR & Mean & Given & 52 & miR-17 \\
\hline
\end{tabular}

Revised Table 2 Subgroup analysis.

\begin{tabular}{|c|c|c|c|c|c|}
\hline \multirow[b]{2}{*}{ Subgroup } & \multirow{2}{*}{$\begin{array}{l}\text { Number of } \\
\text { studies }\end{array}$} & \multicolumn{2}{|l|}{ Heterogeneity } & \multirow[b]{2}{*}{ pooled HR $(95 \% \mathrm{Cl})$} & \multirow[b]{2}{*}{$P$ values } \\
\hline & & $I^{2}(95 \% \mathrm{Cl})$ & $P$ values & & \\
\hline Total & 12 & $38.2 \%$ (0\% to $68.7 \%$ ) & 0.086 & $1.42(1.30$ to 1.55$)$ & $<0.001$ \\
\hline \multicolumn{6}{|l|}{ Ethnic subtotal } \\
\hline Non-Asian & 2 & $71.6 \%$ (0\% to $93.6 \%)$ & 0.06 & $1.48(1.21$ to 1.81$)$ & $<0.001$ \\
\hline Asian & 10 & $36.1 \%(0 \%$ to $69.5 \%)$ & 0.12 & $1.40(1.27$ to 1.55$)$ & $<0.001$ \\
\hline \multicolumn{6}{|l|}{ Disease subtotal } \\
\hline Digestive system & 7 & $34.8 \%$ (0\% to $72.4 \%)$ & 0.163 & $1.36(1.22$ to 1.51$)$ & $<0.001$ \\
\hline Respiratory system & 1 & NA & NA & $1.28(1.02$ to 1.61$)$ & 0.036 \\
\hline Blood system & 2 & 0 & 0.713 & $2.38(1.56$ to 3.63$)$ & $<0.001$ \\
\hline Glioma & 1 & NA & NA & $1.61(1.19$ to 2.18$)$ & 0.002 \\
\hline Osteosarcoma & 1 & NA & NA & $1.61(1.19$ to 2.18$)$ & $<0.001$ \\
\hline \multicolumn{6}{|c|}{ Detected Sample subtotal } \\
\hline Tissue & 10 & $46.2 \%(0 \%$ to $74.1 \%)$ & 0.053 & $1.45(1.31$ to 1.61$)$ & $<0.001$ \\
\hline Serum & 2 & 0 & 0.662 & $1.32(1.10$ to 1.57$)$ & 0.002 \\
\hline
\end{tabular}




\begin{tabular}{|c|c|c|c|c|c|}
\hline \multirow[b]{2}{*}{ Subgroup } & \multirow{2}{*}{$\begin{array}{l}\text { Number of } \\
\text { studies }\end{array}$} & \multicolumn{2}{|l|}{ Heterogeneity } & \multirow[b]{2}{*}{ pooled HR (95\% Cl) } & \multirow[b]{2}{*}{$P$ values } \\
\hline & & $I^{2}(95 \% \mathrm{Cl})$ & $P$ values & & \\
\hline \multicolumn{6}{|c|}{ Detection of miR-17 subtotal } \\
\hline miR-17 & 8 & $60.1 \%(13.2 \%$ to $81.7 \%)$ & 0.057 & $1.29(1.11$ to 1.49$)$ & $<0.001$ \\
\hline miR-17-5p & 4 & $7.5 \%(0 \%$ to $43.4 \%)$ & 0.372 & $1.50(1.34$ to 1.67$)$ & 0.001 \\
\hline
\end{tabular}
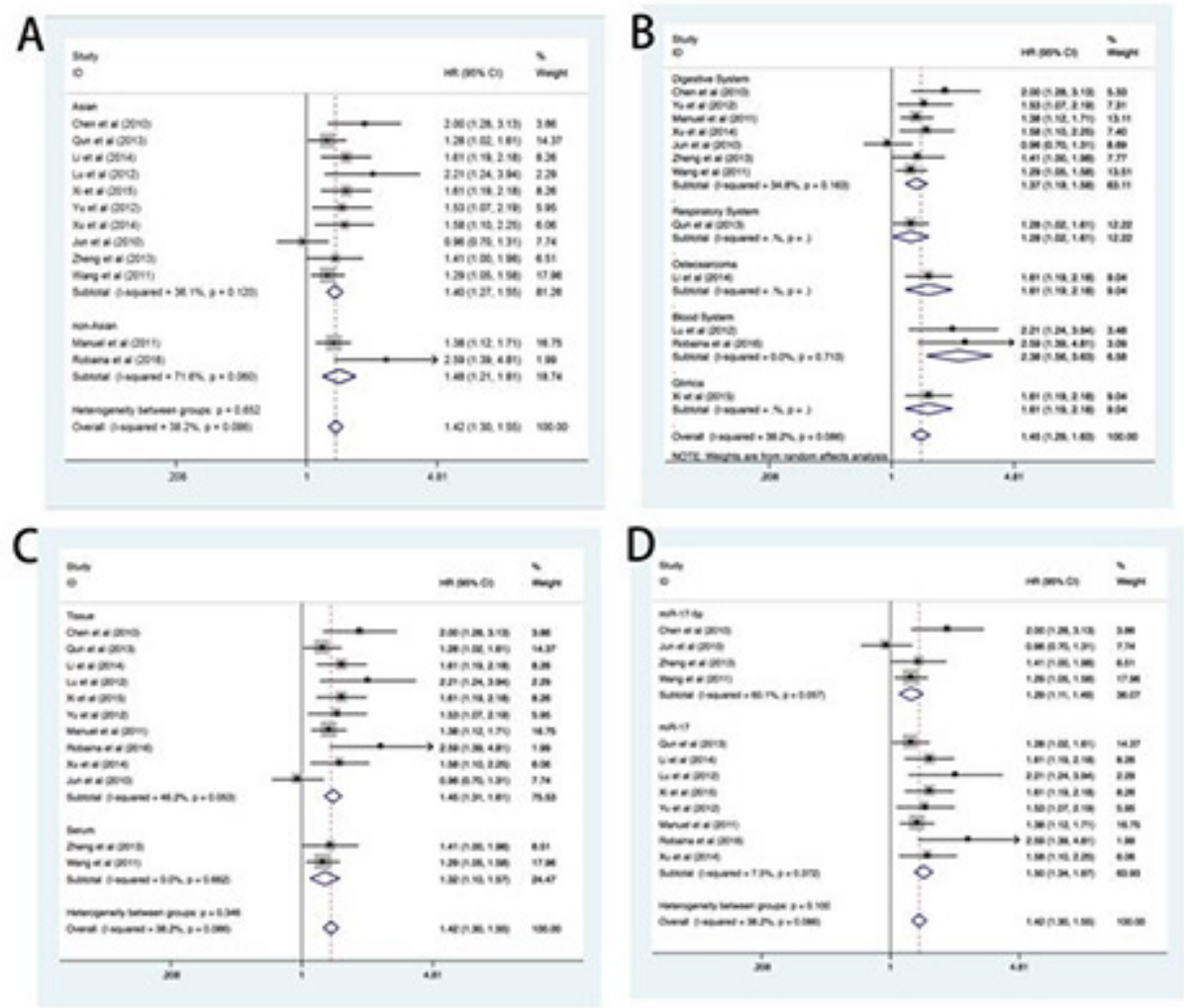

In addition, there were some errors in the 'Abstract' section,under the results subheading, the text should read as:

The results indicated that the increased expression of miR-17 played an unfavourable role in overall survival in various human carcinomas with the HR of 1.342 taking into account the publication bias. In subgroup analysis, HR of ethnicity (non-Asian $\mathrm{HR}=1.48$ and Asian $\mathrm{HR}=1.40$ ), disease (digestive system $\mathrm{HR}=1.36$ and blood system cancer $(\mathrm{HR}=2.38)$ were significant with $\mathrm{P}<0.05$.

This was incorrectly published as: The results indicated that the increased expression of miR-17 played an unfavourable role in overall survival in various human carcinomas with the HR of 1.342 taking into account the publication bias. In subgroup analysis, HR of ethnicity (Caucasian $\mathrm{HR}=1.48$ and Asian $\mathrm{HR}=1.40$ ), disease (digestive system $\mathrm{HR}=1.36$ and blood system cancer $(\mathrm{HR}=2.38)$, detection method (quantitative real-time PCR HR=1.40 and in situ hybridization, HR=2.59) and detection sample (tissue $H R=1.45$ and serum $H R=1.32$ ) were significant with $\mathrm{P}<0.05$.

The errors in the Results section, should read as:

A total of 1096 patients with various types of cancers were from People's Republic of China, Japan, Spain and Brazil. Quantitative real-time PCR (qRT-PCR) was used to assess the expression of miR-17 in all studies. 
and was incorrectly published as:

A total of 1096 patients with various types of cancers were from People's Republic of China, Japan, Spain and Brazil. Quantitative real-time PCR (qRT-PCR) was used to assess the expression of miR-17 in 12 studies, and one study used the in situ hybridisation (ISH).

The errors in the Discussion section, should read as:

In the subgroup analysis, we found that the potential heterogeneity may have originated from the non-Asian group studies.

and was incorrectly published as:

In the subgroup analysis, we found that the potential heterogeneity may have originated from the Caucasian group in the study conducted by Robaina et al. Unlike the commonly used RT-PCR, ISH technique was used to detect miR-17

The errors in the Discussion section, should read as:

However, both studies from Spain and Brazil recruited population of non-Asians decreasing the heterogeneity.

and was incorrectly published as:

However, both studies from Spain and Brazil recruited population of Caucasians decreasing the heterogeneity.

The errors in the Discussion section, should read as:

In subgroup analysis, based on the characteristics of the individual studies, significant HR was found in the non-Asian and Asian groups, and the tissue and serum sample groups.

and was incorrectly published as:

In subgroup analysis, based on the characteristics of the individual studies, significant HR was found in the Caucasian and Asian groups, the qRT-PCR group and the tissue and serum sample groups.

The errors in the Conclusion section, should read as:

However, further multicentre clinical trials with larger sample size and prospective studies including non-Asian and patients representing other ethnicities are needed to confirm the prognostic value of miR-17 and its subsequent application as a prognostic biomarker in the routine clinical guidance of cancers.

and was incorrectly published as:

However, further multicentre clinical trials with larger sample size and prospective studies including Caucasians and patients representing other ethnicities are needed to confirm the prognostic value of miR-17 and its subsequent application as a prognostic biomarker in the routine clinical guidance of cancers.

Revised table 1A summary table of the meta-analysis 


\begin{tabular}{|c|c|c|c|c|c|c|c|c|c|c|c|}
\hline Study & Year & Country & Diseases & $\begin{array}{l}\text { Case } \\
\text { Number }\end{array}$ & Stage & Sample & Assay & $\begin{array}{l}\text { Cut-off } \\
\text { value }\end{array}$ & HR & $\begin{array}{l}\text { Follow-up } \\
\text { (months) }\end{array}$ & $\begin{array}{l}\text { Type of miR- } \\
17 \text { detection }\end{array}$ \\
\hline Chen et al & 2012 & China & $\mathrm{HCC}$ & 120 & I-IV & Tissue & qRT-PCR & Median & $\mathrm{RR}$ & 46 & $m i R-17-5 p$ \\
\hline Li et al & 2014 & China & Osteosarcoma & 117 & I-III & Tissue & qRT-PCR & Median & Given & 44 & $\mathrm{miR}-17$ \\
\hline Lu et al & 2012 & China & Glioma & 108 & I-IV & Tissue & qRT-PCR & Mean & $\mathrm{RR}$ & 60 & $\operatorname{miR}-17$ \\
\hline Yu et al & 2012 & China & Colon Cancer & 48 & I-IV & Tissue & qRT-PCR & Median & Given & $5-66$ & $\operatorname{miR}-17$ \\
\hline Manuel et al & 2011 & Spain & $\begin{array}{l}\text { Gastrointestinal } \\
\text { Cancer }\end{array}$ & 38 & I-IV & Tissue & qRT-PCR & Mean & Given & 38 & $\mathrm{miR}-17$ \\
\hline Robaina et al & 2016 & Brazil & Burkitt lymphoma & 41 & I-IV & Tissue & qRT-PCR & Median & Given & 69 & $\operatorname{miR}-17$ \\
\hline Xu et al & 2014 & China & $\begin{array}{l}\text { Esophageal } \\
\text { Squamous Cell } \\
\text { Carcinoma }\end{array}$ & 105 & I-IV & Tissue & qRT-PCR & Mean & Given & 52 & $\mathrm{miR}-17$ \\
\hline Zheng et al & 2013 & China & $\mathrm{HCC}$ & 96 & I-IV & Serum & qRT-PCR & Median & Given & $N G$ & $m i R-17-5 p$ \\
\hline
\end{tabular}

\begin{tabular}{|c|c|c|c|c|c|}
\hline \multirow[b]{2}{*}{ Subgroup } & \multirow{2}{*}{$\begin{array}{l}\text { Number of } \\
\text { studies }\end{array}$} & \multicolumn{2}{|l|}{ Heterogeneity } & \multirow[b]{2}{*}{ pooled HR $(95 \% \mathrm{Cl})$} & \multirow[b]{2}{*}{$P$ values } \\
\hline & & $I^{2}(95 \% \mathrm{Cl})$ & $P$ values & & \\
\hline Total & 12 & $38.2 \%(0 \%$ to $68.7 \%) \%)$ & 0.086 & $1.42(1.30$ to 1.55$)$ & $<0.001$ \\
\hline \multicolumn{6}{|l|}{ Ethnic subtotal } \\
\hline Non-Asian & 2 & $71.6 \%(0 \%$ to $93.6 \%) \%)$ & 0.06 & $1.48(1.21$ to 1.81$)$ & $<0.001$ \\
\hline Asian & 10 & $36.1 \%$ (0\% to $69.5 \%) \%)$ & 0.12 & 1.40 (1.27 to 1.55$)$ & $<0.001$ \\
\hline \multicolumn{6}{|l|}{ Disease subtotal } \\
\hline Digestive system & 7 & $34.8 \%(0 \%$ to $72.4 \%) \%)$ & 0.163 & $1.36(1.22$ to 1.51$)$ & $<0.001$ \\
\hline Respiratory system & 1 & NA & NA & 1.28 (1.02 to 1.61$)$ & 0.036 \\
\hline Blood system & 2 & 0 & 0.713 & 2.38 (1.56 to 3.63$)$ & $<0.001$ \\
\hline Glioma & 1 & NA & NA & 1.61 (1.19 to 2.18$)$ & 0.002 \\
\hline Osteosarcoma & 1 & NA & NA & 1.61 (1.19 to 2.18 ) & $<0.001$ \\
\hline \multicolumn{6}{|c|}{ Detected Sample subtotal } \\
\hline Tissue & 10 & $46.2 \%(0 \%$ to $74.1 \%) \%)$ & 0.053 & $1.45(1.31$ to 1.61$)$ & $<0.001$ \\
\hline Serum & 2 & 0 & 0.662 & $1.32(1.10$ to 1.57$)$ & 0.002 \\
\hline \multicolumn{6}{|c|}{ Detection of miR-17 subtotal } \\
\hline $\mathrm{miR}-17$ & 8 & $60.1 \%(13.2 \%$ to $81.7 \%) \%)$ & 0.057 & 1.29 (1.11 to 1.49$)$ & $<0.001$ \\
\hline miR-17-5p & 4 & $7.5 \%$ (0\% to $43.4 \%) \%)$ & 0.372 & 1.50 (1.34 to 1.67$)$ & 0.001 \\
\hline
\end{tabular}

Open access This is an open access article distributed in accordance with the Creative Commons Attribution Non Commercial (CC BY-NC 4.0) license, which permits others to distribute, remix, adapt, build upon this work non-commercially, and license their derivative works on different terms, provided the original work is properly cited, appropriate credit is given, any changes made indicated, and the use is non-commercial. See: http://creativecommons.org/licenses/by-nc/4.0/.

(C) Author(s) (or their employer(s)) 2018. Re-use permitted under CC BY-NC. No commercial re-use. See rights and permissions. Published by BMJ.

BMJ Open 2018;8:e018070corr1. doi:10.1136/bmjopen-2017-018070corr1 